\title{
Effect of laser welding parameters on the austenite and martensite phase fractions of $\mathrm{NiTi}$
}

\author{
J.P. Oliveira ${ }^{\mathrm{a}, *}$, F.M. Braz Fernandes ${ }^{\mathrm{a}}$, R.M. Miranda ${ }^{\mathrm{b}}$, N. Schell ${ }^{\mathrm{c}}$, J.L. Ocaña ${ }^{\mathrm{d}}$ \\ ${ }^{a}$ CENIMAT/i3N, Faculdade de Ciências e Tecnologia, Universidade Nova de Lisboa, Portugal \\ ${ }^{\mathrm{b}}$ UNIDEMI, Faculdade de Ciências e Tecnologia, Universidade Nova de Lisboa, Portugal \\ ${ }^{c}$ Institute of Materials Research, Helmholtz-Zentrum Geesthacht, Max-Planck-Str. 1, D-21502 Geesthacht, Germany \\ d Centro Láser UPM, Universidad Politécnica de Madrid, Edificio "La Arboleda", Ctra. Valencia, km 7,300, Campus Sur UPM, 28031 Madrid, Spain
}

\section{A R T I C L E IN F O}

Article history:

Received 1 July 2016

Received in revised form 30 July 2016

Accepted 1 August 2016

Available online xxx

Keywords:

Shape memory alloys (SMA)

Laser welding

Synchrotron radiation

Phase fraction

Phase transformations

\section{A B S T R A C T}

Although laser welding is probably the most used joining technique for NiTi shape memory alloys there is still a lack of understanding about the effects of laser welding parameters on the microstructural induced changes: in both the heat affected and fusion zones martensite may be present, while the base material is fully austenitic. Synchrotron X-ray diffraction was used for fine probing laser welded NiTi joints. Through Rietveld refinement the martensite and austenite phase fractions were determined and it was observed that the martensite content increases towards the weld centreline. This is related to a change of the local transformation temperatures on these regions, which occurs due to compositional variation in those regions. The martensite phase fraction in the thermally affected regions may have significant implications on functional properties on these joints.

CC 2016 Published by Elsevier Ltd.

\section{Introduction}

In order to obtain complex shaped structures using NiTi shape memory alloys joining methods are required owing to the poor machinability of these materials [1]. Among the different joining techniques available, fusion-based ones, such as tungsten inert gas (TIG) [2] and laser welding [3-6], have presented the best results in terms of the mechanical properties of the joints. Laser welding is by far the most used process for welding NiTi due to the reduced extension of the thermally affected regions, which is especially important for NiTi due to the deterioration of its functional properties (shape memory effect and superelasticity) at high temperatures.

It was observed that laser welding is responsible for a change of the local chemical composition, thus changing the transformation temperatures of those thermally affected regions. Namely, an originally fully austenitic base material can present either martensite or a mixture of both martensite and austenite in those regions after welding.

Conventional analytical techniques for determining the phase transformation characteristics of NiTi shape memory alloys are differential scanning calorimetry (DSC) $[7,8]$ and X-ray diffraction $[9,10]$ using conventional lab sources. However, these techniques are not suited to provide the spatial resolution required for an in-depth understanding of the microstructural changes occurring along both the heat affected and fusion zones due to the laser welding procedure. While for DSC it is not possible to ensure that only the heat affected

* Corresponding author.

Email address: jp.oliveira@campus.fct.unl.pt (J.P. Oliveira) or fusion zone are being analysed [6], these regions tend also to present a microstructural gradient thus preventing a reliable analysis of the phase transformation characteristics. Additionally, for X-ray diffraction analysis using conventional lab sources, it is known that in the Bragg-Brentano geometry, often used for such analysis, does not ensure the required spatial resolution for detailed analysis of the thermally affected regions.

A possible way to surpass this setback is with the use of high energy synchrotron-based X-ray diffraction operating in transmission mode. Owing to the high photon flux of these sources, the beam spot size can be very narrow, while still providing good statistics [11]. Additionally, it is possible to obtain precise control of the beam position, ensuring that the analysed region corresponds entirely to a given region. If necessary, it is still possible to probe the material within these thermally affected regions, in order to determine the existence of any microstructural gradient.

In this work, synchrotron X-ray diffraction was used for fine probing the different regions of laser welded NiTi joints. This is the first investigation addressing the effect of laser welding parameters on the phase content in the thermally affected regions of NiTi welds.

\section{Experimental Procedure}

Ni-rich NiTi shape memory alloys, $50.8 \mathrm{at} \% \mathrm{Ni}$, superelastic at room temperature, purchased from Memry in the flat annealed condition, were used in this investigation in the form of $1 \mathrm{~mm}$ thick plate. Differential scanning calorimetry (DSC) of the base material was performed in a temperature range between $-160^{\circ} \mathrm{C}$ and $70{ }^{\circ} \mathrm{C}$, at a heating/cooling rate of $10{ }^{\circ} \mathrm{C} / \mathrm{min}$, to determine its transformation 
temperatures. It was confirmed that, at room temperature, the material was fully austenitic.

Laser butt welding of $30 \times 30 \mathrm{~mm}$ NiTi plates was performed using a Nd:YAG laser from Rofin Sinar, operating in continuous wave mode. The base material was cleaned using alcohol and acetone, prior to welding, to remove impurities. Two distinct welding conditions (varying power, $\mathrm{P}$, and welding speed, $\mathrm{v}$ ) were selected in order to ensure that full penetration was achieved, with no microstructural defects, such as porosity or lack of penetration. The selected welding parameters were: a) $P=990 \mathrm{~W}$ and $\mathrm{v}=25 \mathrm{~mm} / \mathrm{s}$, for sample A; b) $P=1485 \mathrm{~W}$ and $\mathrm{v}=20 \mathrm{~mm} / \mathrm{s}$, for sample B. So, it was ensured that significantly different heat inputs $(\mathrm{HI})$, which is defined as the power $(\mathrm{P})$ to welding speed $(\mathrm{v})$ ratio $(\mathrm{P} / \mathrm{v})$, allowed obtaining defect-free joints. Shielding gases were used to prevent oxidation: argon on the face and helium on the root. The flow rate of the protection gases was set at $40 \mathrm{l} / \mathrm{min}$ for Ar and $501 / \mathrm{min}$ for He.

Microstructural characterization by means of X-ray diffraction analysis using synchrotron radiation was performed at beamline P07 High Energy Materials Science of Petra III/DESY. A high energy beam of $87 \mathrm{keV}$ (corresponding to a wavelength of $0.1426 \AA$ ) was used and the sample to the $2 \mathrm{D}$ detector Mar345 was set at $1.35 \mathrm{~m}$.
The beam spot was a $200 \times 200 \mu \mathrm{m}^{2}$. The samples were analysed perpendicularly to the weld bead, starting in the base material, going through the heat affected and fusion zones and finishing on the other side on the base material. A length of nearly $6 \mathrm{~mm}$ was probed with a distance of $200 \mu \mathrm{m}$ between two adjacent analysed spots. All X-ray diffraction analysis was performed at room temperature.

The raw 2D images were treated using Fit2D [12] as described in [13]. Determination of the phase fraction of the existing phases at each analysed spot was performed using Rietveld code available in Material Analysis Using Diffraction (MAUD) program [14].

\section{Results and Discussion}

The X-ray diffractograms of samples A and B at room temperature exhibit similar information: while the base material is fully austenitic, the thermally affected regions present a mixture of both austenite and martensite (Fig. 1). The formation of this thermally stable martensite occurs by two distinct reasons:

(i) in the heat affected zone, $\mathrm{Ni}_{4} \mathrm{Ti}_{3}$ precipitation increases the transformation temperatures allowing for martensite to be stable at room temperature $[15,16]$,
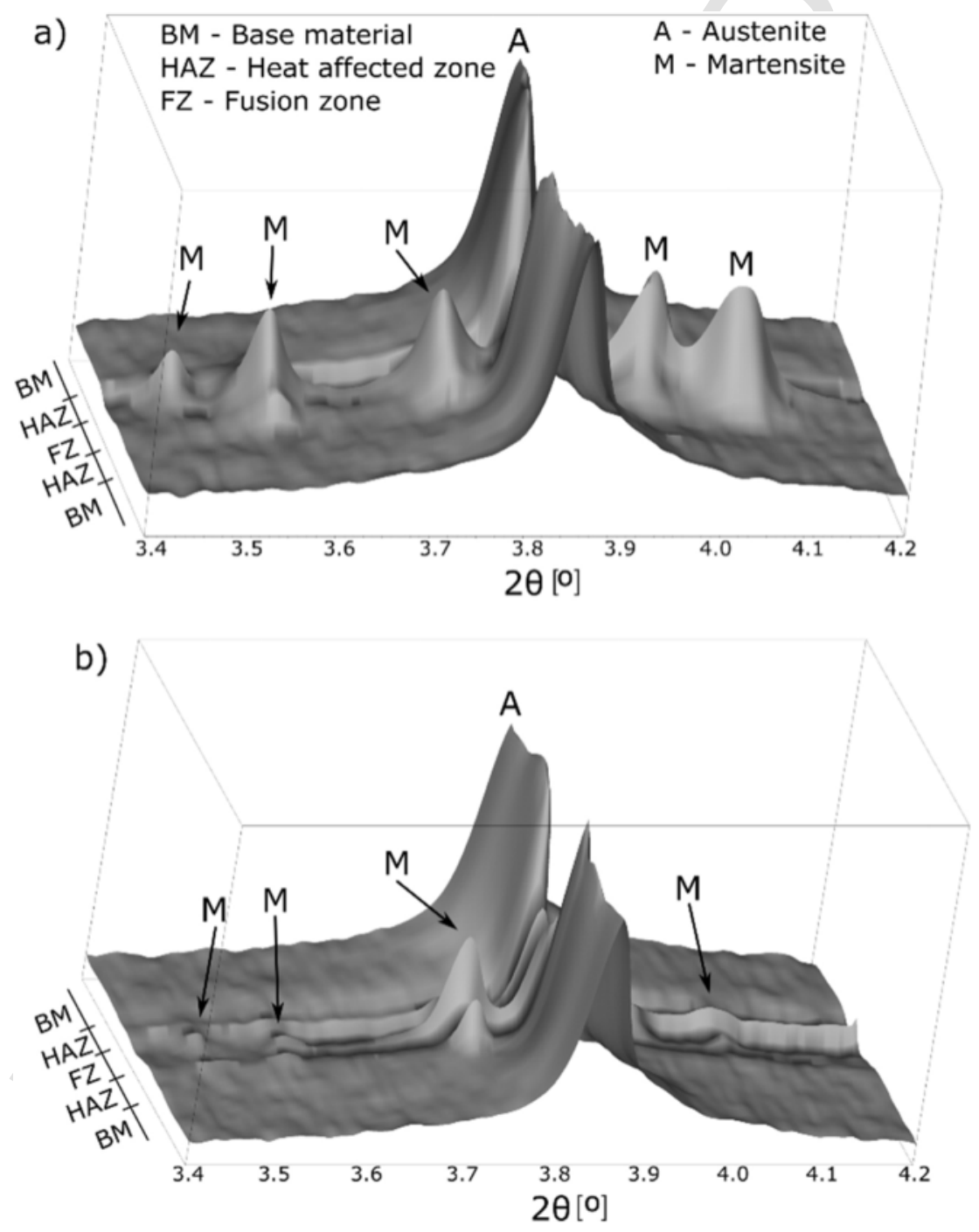

Fig. 1. X-ray diffraction patterns of samples A (a) and B (b). 
(ii) in the fusion zone, preferential Ni volatilization has the same effect of increasing the transformation temperature in this region $[15,17]$.

As a consequence of this increase of the transformation temperatures, different amounts of martensite, which will vary on each analysed region, will be stable at room temperature in coexistence with austenite. It can also be observed the effect of the heat input on the extension of the thermally affected regions: the higher heat input, gives a larger extension of those regions.

The precipitation of $\mathrm{Ni}_{4} \mathrm{Ti}_{3}$ in the heat affected zone will not be homogenous throughout this region. The reason for this is related to the permanence times at temperatures which enable for this phenomenon to occur: near the fusion zone, the permanence times will be higher, thus more $\mathrm{Ni}_{4} \mathrm{Ti}_{3}$ precipitation will occur, promoting a more significant change in the chemical composition of the surrounding matrix and thus allowing for more martensite to be stable at room temperature; on the other hand, closer to the base material, the permanence times at the interval range required for precipitation is shorter, thus resulting in less martensite formed at room temperature, due to a lower compositional change. As such, the martensite content increases from the base material/heat affected zone interface towards the heat affected zone/fusion zone interface. In the fusion zone similar compositional changes occur allowing for martensite formation: at the weld centreline the Ni volatilization will be significantly higher than near the heat affected zone, as a result of the increased temperatures reached in the first region. As such, more martensite is stable near the weld centreline. It is known that for Ni-rich NiTi shape memory alloys any decrease in Ni content promotes a significant raise of the transformation temperature [18]. The permanence times in the temperature range of 350 to $500{ }^{\circ} \mathrm{C}$ where $\mathrm{Ni}_{4} \mathrm{Ti}_{3}$ precipitation may occur can be calculated using the Rosenthal equation as presented in [15]. For the welding parameters chosen, the holding time, in the temperature range where precipitation may occur, ranged between 3 and $30 \mathrm{~s}$.

Rietveld refinement was used to determine the phase fraction of martensite and austenite in both the heat affected and fusion zone of these laser welded NiTi joints. Good agreement between the calculated and experimental patterns in terms of width, position and intensity was observed after Rietveld refinement (Fig. 2), thus indicating a good fit [19].

A clear distinction between the heat affected zone and fusion zone is observed for both samples: while in the former the martensite phase fraction ranges between 4 and $20 \%$, in the latter a significant increase to roughly $50 \%$ of martensite is observed, as shown in Fig. 3. These results are in line with the aforementioned relative importance of the mechanisms that promote Ni depletion: precipitation in the heat affected zone changes less the chemical composition than preferential volatilization occurring in the fusion zone, thus justifying the sharp difference in the martensite content in both regions.

An increase in the martensite phase fraction is observed from the base material/heat affected zone interface to the weld centreline (Fig. $3)$. However, that variation is more notorious in the fusion zone. The preferential $\mathrm{Ni}$ evaporation occurring during keyhole welding in the fusion has a greater influence as it promotes a higher Ni depletion than in the heat affected zone, thus allowing for more martensite to exist in this region, when compared to the heat affected zone.

Considering the heat input of both welded samples, it was also observed that the difference in austenite or martensite phase fractions is not significant, with those differences ranging around $5 \%$ for equivalent points on both samples. Such minor differences occur by two reasons: in the fusion zone the temperatures reached are higher for sample A (due to higher heat input introduced during welding); in the heat affected zone the permanence time for Ni-rich precipitation is also higher for sample A.

\section{Conclusions}

In conclusion, synchrotron X-ray diffraction was used for fine probing of laser butt welded NiTi joints. As a consequence of the welding procedure, martensite is formed in the thermally affected regions, while the base material maintains its fully austenitic original structure.

The martensite phase fraction varies from the heat affected zone to the weld metal and within each zone, that is, the amount of martensite in the fusion zone is higher than in the heat affected zone. Additionally, the martensite content increases in the heat affected zone towards the fusion zone, due to higher temperatures experienced during welding. Such feature is also observed in the fusion zone but with a different underlying mechanism: in the heat affected zone Ni-rich precipitation promotes a local modification of the matrix composition, hence raising the transformation temperatures and allowing for martensite to be stable at room temperature; in the fusion zone, preferential $\mathrm{Ni}$ volatilization has the same effect of raising the transformation temperatures.

Using Rietveld refinement, it was possible to observe that the martensite phase fraction increases from the base material/heat af-

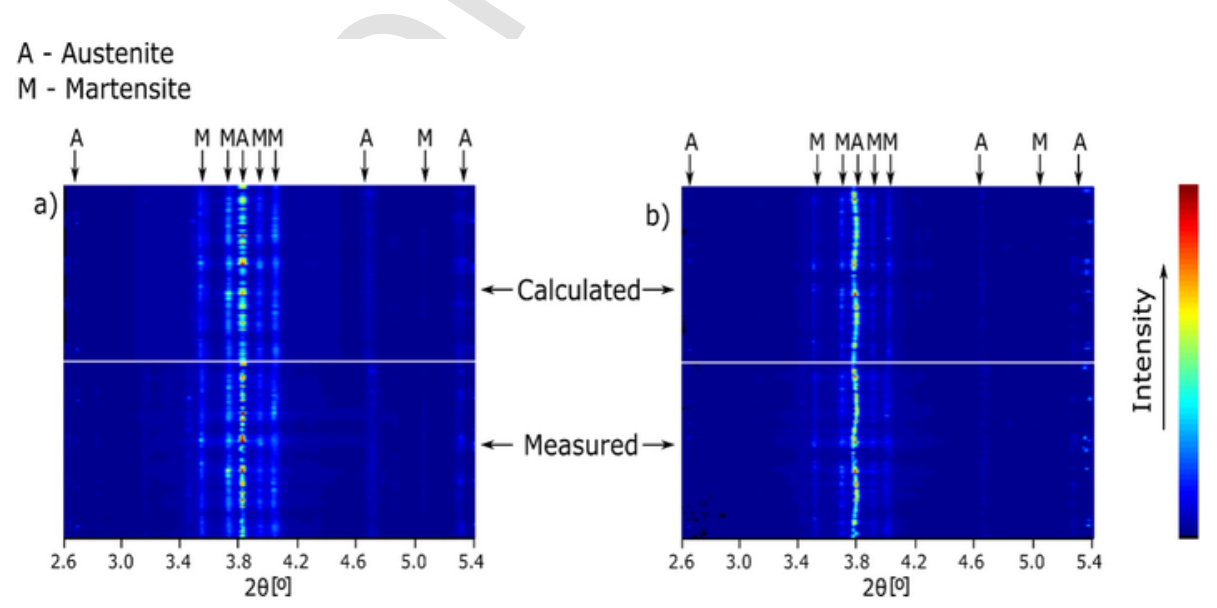

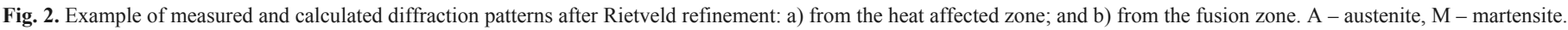




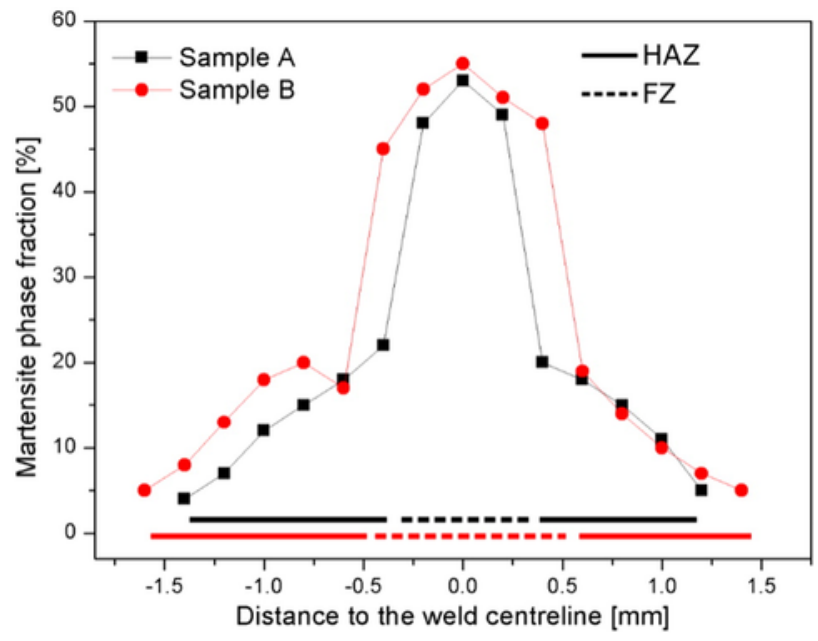

Fig. 3. Evolution of the martensite phase fraction in samples A and B. HAZ - heat affected zone; FZ - fusion zone.

fected zone interface towards the weld centreline. Within the heat affected zone, the martensite phase fraction increases towards the fusion zone, as a result of longer periods for precipitation phenomena. This precipitation process is responsible for the increase of the transformation temperatures due to a local compositional change of the surrounding matrix, giving rise to the formation of martensite at room temperature.

It can be inferred from these results that the local transformation temperatures should differ from point to point in the thermally affected regions. The determination of these transformation temperatures using in-situ techniques would be of great interest to determine the feasibility of obtaining a gradient of functional properties aiming applications that may require laser welded NiTi joints.

\section{Acknowledgments}

Funding of CENIMAT/I3N by FEDER funds through the COMPETE 2020 Program and National Funds through FCT- Portuguese Foundation for Science and Technology under the project UID/CTM/ $50025 / 2013$ is acknowledged by JPO and FBF. Funding of UNIDEMI by FEDER funds through the COMPETE 2020 Program and National Funds through FCT - Portuguese Foundation for Science and Technology under the project UID/EMS/00667/2013 is acknowledged by RMM. The authors acknowledge DESY and HZG for beam time and travel reimbursement under proposall-20120563 EC FP7/ 2007-2013 grant agreement no. 312284. JPO acknowledges FCT/ MCTES for funding PhD grant SFRH/BD/85407/2012.

\section{References}

[1] K. Weinert, V. Petzoldt, Machining NiTi micro-parts by micro-milling, Mater. Sci. Eng. A 481-482 (2008) 672-675, http://dx.doi.org/10.1016/j.msea.2006.10. 220 .
[2] J.P. Oliveira, D. Barbosa, F.M.B. Fernandes, R.M. Miranda, Tungsten inert gas (TIG) welding of Ni-rich NiTi plates: functional behavior, Smart Mater. Struct. 25 (2016) 03LT01, http://dx.doi.org/10.1088/0964-1726/25/3/03LT01.

[3] A. Tuissi, S. Besseghini, T. Ranucci, F. Squatrito, M. Pozzi, Effect of Nd-YAG laser welding on the functional properties of the Ni-49.6 at.\%Ti, Mater. Sci. Eng. A 273-275 (1999) 813-817, http://dx.doi.org/10.1016/ S0921-5093(99)00422-0.

[4] H. Gugel, A. Schuermann, W. Theisen, Laser welding of NiTi wires, Mater. Sci. Eng. A 481-482 (2008) 668-671, http://dx.doi.org/10.1016/j.msea.2006.11.179.

[5] J.P. Oliveira, R.M. Miranda, F.M. Braz Fernandes, High strain and long duration cycling behavior of laser welded NiTi sheets, Int. J. Fatigue 83 (2015) 195-200, http://dx.doi.org/10.1016/j.ijfatigue.2015.10.013.

[6] Y.G. Song, W.S. Li, L. Li, Y.F. Zheng, The influence of laser welding parameters on the microstructure and mechanical property of the as-jointed NiTi alloy wires, Mater. Lett. 62 (2008) 2325-2328, http://dx.doi.org/10.1016/j.matlet. 2007.11.082.

[7] T.G. Bradley, W.A. Brantley, B.M. Culbertson, Differential scanning calorimetry (DSC) analyses of superelastic and nonsuperelastic nickel-titanium orthodontic wires, Am. J. Orthod. Dentofac. Orthop. 109 (1996) 589-597, http://dx. doi.org/10.1016/S0889-5406(96)70070-7.

[8] D. Yang, H.C. Jiang, M.J. Zhao, L.J. Rong, Microstructure and mechanical behaviors of electron beam welded NiTi shape memory alloys, Mater. Des. 57 (2014) 21-25, http://dx.doi.org/10.1016/j.matdes.2013.12.039.

[9] Y. Liu, D. Favier, Stabilisation of martensite due to shear deformation via variant reorientation in polycrystalline NiTi, Acta Mater. 48 (2000) 3489-3499, http://dx.doi.org/10.1016/S1359-6454(00)00129-4.

[10] K.Y. Chiu, F.T. Cheng, H.C. Man, A preliminary study of cladding steel with NiTi by microwave-assisted brazing, Mater. Sci. Eng. A 407 (2005) 273-281, http://dx.doi.org/10.1016/j.msea.2005.07.013.

[11] K.-D. Liss, A. Bartels, A. Schreyer, H. Clemens, High-energy X-rays: a tool for advanced bulk investigations in materials science and physics, Textures $\mathrm{Mi}$ crostruct. 35 (2003) 219-252, http://dx.doi.org/10.1080/ 07303300310001634952

[12] A.P. Hammersley, S.O. Svensson, M. Hanfland, A.N. Fitch, D. Hausermann, Two-dimensional detector software: from real detector to idealised image or two-theta scan, High Pressure Res. 14 (1996) 235-248, http://dx.doi.org/10. 1080/08957959608201408

[13] J.P. Oliveira, F.M.B. Fernandes, R.M. Miranda, N. Schell, J.L. Ocaña, Residual stress analysis in laser welded NiTi sheets using synchrotron X-ray diffraction, Mater. Des. 100 (2016) 180-187, http://dx.doi.org/10.1016/j.matdes.2016.03. 137.

[14] L. Lutterotti, S. Matthies, H.-R. Wenk, A.S. Schultz, J.W. Richardson, Combined texture and structure analysis of deformed limestone from time-of-flight neutron diffraction spectra, J. Appl. Phys. 81 (1997) 594, http://dx.doi.org/10. 1063/1.364220.

[15] J.P. Oliveira, F.M. Braz Fernandes, R.M. Miranda, N. Schell, On the mechanisms for martensite formation in YAG laser welded austenitic NiTi, Shape Mem. Superelasticity 2 (2016) 114-120, http://dx.doi.org/10.1007/ s40830-016-0058-z.

[16] J.P. Oliveira, F.M.B. Fernandes, N. Schell, R.M. Miranda, Martensite stabilization during superelastic cycling of laser welded NiTi plates, Mater. Lett. 171 (2016) 273-276, http://dx.doi.org/10.1016/j.matlet.2016.02.107.

[17] X.J. Yan, D.Z. Yang, Corrosion resistance of a laser spot-welded joint of NiTi wire in simulated human body fluids, J. Biomed. Mater. Res. A 77 (2006) 97-102, http://dx.doi.org/10.1002/jbm.a.30378.

[18] J.K. Allafi, X. Ren, G. Eggeler, The mechanism of multistage martensitic transformations in aged Ni-rich NiTi shape memory alloys, Acta Mater. 50 (2002) 793-803, http://dx.doi.org/10.1016/S1359-6454(01)00385-8.

[19] H.-R. Wenk, L. Lutterotti, P. Kaercher, W. Kanitpanyacharoen, L. Miyagi, R. Vasin, Rietveld texture analysis from synchrotron diffraction images. II. Complex multiphase materials and diamond anvil cell experiments, Powder Diffract. 4 (2014) 1-13, http://dx.doi.org/10.1017/S0885715614000360. 